In the Studio 



\section{In the Studio}

Visual Creation and

Its Material Environments

Edited by Brian R. Jacobson

\section{甲ㅜ}

UNIVERSITY OF CALIFORNIA PRESS 
University of California Press

Oakland, California

(C) 2020 by Regents of the University of California

Library of Congress Cataloging-in-Publication Data

Names: Jacobson, Brian R., editor.

Title: In the studio : visual creation and its material environments / edited by Brian R. Jacobson.

Description: Oakland, California : University of California Press, [2020] | Includes bibliographical references and index.

Identifiers: LCCN 2019058278 (print) | LCCN 2019058279 (ebook) | ISBN 9780520297593 (cloth) | ISBN 9780520297609 (paperback) | ISBN 9780520969896 (ebook) LCSH: Motion picture studios-History2oth century.

Classification: LCC PN1993.5.A1 I49 2020 (print) | LCC PN1993.5.A1 (ebook) | DDC 384/.85-dc23

LC record available at https://lccn.loc.gov/2019058278

LC ebook record available at https://lccn.loc.gov/2019058279

Manufactured in the United States of America

$\begin{array}{llllllll}27 & 26 & 25 & 24 & 23 & 22 & 21 & 20\end{array}$

$\begin{array}{llllllllll}10 & 9 & 8 & 7 & 6 & 5 & 4 & 3 & 2 & 1\end{array}$ 